\title{
Evaluasi Penerapan Metode Uji ASTM D-86 Untuk Penentuan Sifat Volatility Solar B30
}

\author{
Arluky Novandy \\ Pusat Pengembangan Sumber Daya Manusia Minyak dan Gas Bumi, Cepu
}

\begin{abstract}
INFORMASI NASKAH ABSTRAK
Diterima: 25 Februari 2021 Uji distilasi merupakan salah satu parameter uji yang penting Direvisi: 28 Juni 2021

Disetujui: 30 Juni 2021

Terbit: 30 Juni 2021 dalam penentuan kualitas bahan bakar, khususnya pada penentuan sifat penguapan bahan bakar. Pada spesifikasi jenis bahan bakar minyak Solar yang dipasarkan di dalam negeri, metode distilasi yang digunakan adalah ASTM D86-17. Penelitian ini membahas

Email korespondensi: mengenai evaluasi penerapan metode distilasi ASTM D86-17 uthemigas2003@gmail.com pada Biosolar B30. Uji F menunjukkan bahwa metode ASTM D86-17 dapat digunakan untuk distilasi Biosolar B30 sedangkan

Laman daring:

https://doi.org/10.37525/

$\mathrm{mz} / 2021-1 / 277$ Uji t menunjukkan bahwa rerata (mean) data distilasi Solar kilang dan Biosolar B30 tidak sama sehingga terdapat perbedaan yang signifikan.
\end{abstract}

Kata kunci: B30, Distilasi, F-test, Solar, t-test

\section{ABSTRACT}

The distillation test is one of the important test parameters in determining the quality of fuel, especially in determining the volatility characteristic. In the domestic market for diesel fuel types, the distillation method used is ASTM D86-17. This study discusses the analysis of the application of the ASTM D86-17 distillation method on Biosolar B30. The F test shows that the ASTM D8617 method can be used for the distillation of Biosolar B30, while the t test shows that the mean of refinery diesel and biodiesel B30 distillation data are not the same so there is a significant difference.

Keywords: B30, diesel, distillation, F-test, t-test 


\section{PENDAHULUAN}

Kementerian Energi dan Sumber Daya Mineral melalui Siaran Pers Nomor 712/04/ SJI/2019 pada tanggal 23 Desember 2019 menyatakan narasi tunggal bahwa Indonesia menjadi Negara pertama di dunia yang menerapkan Biosolar 30 persen (B30). Dengan adanya pernyataan tersebut maka B30 merupakan bahan bakar alternative pengganti Solar murni, sehingga Kementerian ESDM Direktorat Minyak dan Gas Bumi Indonesia mengeluarkan Keputusan Dirjen Migas Nomor 146.K/10/DJM/2020 mengenai spesifikasi bahan bakar yang dipasarkan didalam negeri, salah satunya adalah Biosolar B30. Dalam spesifikasi tersebut terdiri dari beberapa karakteristik, salah satunya adalah distilasi. Suhu distilasi merupakan indikator volatilitas dan pembakaran yang karakteristik pada setiap bahan bakar cair (Lin and Ma, 2020) Suhu distilasi tersebut berperan penting dalam penentuan indeks setana yang menentukan tingkat kualitas dari suatu bahan bakar. Menurut keputusan Direktorat Jenderal Minyak dan Gas Bumi, penentuan suhu penguapan distilasi bahan bakar Solar dan Biosolar B30 dilakukankan menggunakan metode ASTM D86-17. Namun, menurut metode ASTM D86-17 (section 1.1 page 1), metode hanya berlaku hingga kandungan campuran Biosolar sebesar 20\% yaitu Biosolar B20. Adanya ketidaksesuaian penerapan metode ASTM D86-17 tersebut mendasari penelitian ini dalam pengujian penerapan distilasi Biosolar B30 menggunakan metode ASTM D86-17 mengenai bisa tidaknya metode tersebut diterapkan dalam penentuan uji distilasi Biosolar B30. Penelitian sebelumnya yang telah dilakukan oleh Araujo et. al., 2021, dilakukan uji distilasi pada Biosolar jenis B5, B10, B15, B20, B30, dan B50 menggunakan metode standar ASTM D86-17.

\section{METODE PENELITIAN}

Penelitian diawalai dengan uji distilasi sampel menggunakan metode ASTM D86-17. Tangki distilator diisi menggunakan air hangat pada suhu $20^{\circ} \mathrm{C}-60^{\circ} \mathrm{C}$. Sebanyak $100 \mathrm{~mL}$ sampel dimasukan kedalam flask dan ditutup menggunakan penutup dengan thermometer ASTM 8C. Heater dinyalakan bersamaan dengan pengaturan timer, dimana Initial Boiling Point (IBP) berada pada rentang waktu 5-15 menit. Laju alir distilasi setelah IBP diatur $4-5 \mathrm{~mL} / \mathrm{menit}$. Suhu setiap 10\% volume recovery dicatat hingga $90 \%$ recovery. Pada suhu $370^{\circ} \mathrm{C}$ distilasi diberhentikan, jika sebelumnya terjadi penurunan suhu maka temperatur tertinggi sebelum penurunan dicatat sebagai Final Boiling Point (FBP). Pengamatan FBP mulai dilakukan saat 95\% recovery tercapai.

Pengujian metode distilasi D86-17 untuk Biosolar B30 dilakukan dengan menguji keseragaman hasil distilasi menggunakan distribusi normal yang dilanjutkan dengan uji $F$ dan uji t. Uji $F$ digunakan untuk membandingkan varians antara dua kumpulan data guna menentukan ada tidaknya perbedaan presisi data dalam statistik, sedangkan uji $\mathrm{t}$ digunakan untuk membandingakan rerata (mean) dari dua kumpulan data guna menentukan ada tidaknya perbedaan yang signifikan dari kedua data tersebut.

$$
\begin{aligned}
& \text { Mean } \\
& \bar{X}=\frac{\sum X_{i}}{n}=\frac{X_{1}+X_{2}+\cdots+X_{n}}{n}
\end{aligned}
$$

$$
\begin{aligned}
& \text { Standar Deviasi } \\
& s=\sqrt{\frac{\sum\left(X_{i}-\bar{X}\right)^{2}}{n-1}} \\
& =\sqrt{\frac{\left(X_{1}-\bar{X}\right)^{2}+\left(X_{2}-\bar{X}\right)^{2}+\cdots+\left(X_{n}-\bar{X}\right)^{2}}{n-1}}
\end{aligned}
$$




$$
\begin{aligned}
& \text { z-score } \\
& z-\text { score }: \frac{\left(X_{i}-\bar{X}\right)}{s} \\
& \text { Upper Control Limit (confidence level 95\%) } \\
& \backslash U C L=\bar{X}+2 s
\end{aligned}
$$

\section{Lower Control Limit (confidence level 95\%)} $L C L=\bar{X}-2 s$

\section{Standar Deviasi Relatif}

$\% R S D=\frac{S}{\bar{X}} \times 100 \%$

$$
T=\frac{\bar{X}_{a}-\overline{X_{b}}}{s_{p} \sqrt{\frac{1}{n_{a}}+\frac{1}{n_{b}}}}
$$

\section{HASIL PENELITIAN DAN PEMBAHA- SAN}

Dalam pengujian keseragaman hasil distilasi dilakukan perhitungan Upper Control Limit (UCL) dan Lower Control Limit (LCL) guna mengetahui apakah terdapat pencilan data. Dari hasil uji keseragaman menggunakan confidence level 95\% diperoleh bahwa tidak terdapat pencilan data hasil distilasi baik dari Solar kilang maupun Biosolar B30, sehingga data tersebut dapat dianalisis lebih lanjut menggunakan F-test dan t-test guna mengetahui nilai rerata (mean) dan varians populasi dari kedua data hasil distilasi.

Untuk menguji hipotesis bahwa varians antara Solar kilang dan Biosolar B30 dari dua populasi yang sama $\left(\sigma_{1}^{2}=\sigma^{2}\right)$, maka dilakukan uji F. Uji $F$ dilakukan guna menentukan kecermatan metode yang digunakan dalam pengukuran sampel secara berulangan. Pada penelitian ini uji $\mathrm{F}$ dilakukan dengan confidence level sebesar 95\%.

Dari table diperoleh bahwa nilai dari F-hitung < F-tabel sehingga hipotesis H0 diterima, maka varians dari kedua sampel, Solar kilang dan Biosolar B30, adalah sama. Hal ini menunjukkan bahwa pada uji standar ASTM D86-17 dapat digunakan sebagai metode uji distilasi solar B30 pada confidence level 95\%. Hasil tersebut didukung dengan penelitian sebelumnya yang telah dilakukan

\begin{tabular}{|c|c|c|c|c|c|c|c|c|c|c|c|c|c|}
\hline SOLAR KILANG & 1 & 2 & 3 & 4 & 5 & 6 & 7 & $M E A N$ & SD & UCL & LCL & RSD & KET \\
\hline IBP & 163 & 169 & 160 & 160 & 168 & 160 & 164 & 163,429 & 3,823 & 171,076 & 155,782 & 2,340 & $\mathrm{IN}$ \\
\hline T10\% Recovery & 196 & 204 & 200 & 189 & 196 & 198 & 200 & 197,571 & 4,997 & 207,565 & 187,578 & 2,529 & $\mathrm{IN}$ \\
\hline T20\% Recovery & 212 & 224 & 220 & 205 & 212 & 215 & 210 & 214,000 & 6,683 & 227,367 & 200,633 & 3,123 & IN \\
\hline T30\% Recovery & 228 & 241 & 240 & 221 & 228 & 231 & 230 & 231,286 & 7,714 & 246,713 & 215,858 & 3,335 & IN \\
\hline T40\% Recovery & 242 & 256 & 256 & 239 & 244 & 244 & 240 & 245,857 & 7,333 & 260,522 & 231,192 & 2,982 & IN \\
\hline T50\% Recovery & 256 & 270 & 270 & 258 & 262 & 260 & 265 & 263,000 & 6,022 & 275,044 & 250,956 & 2,290 & $\mathrm{IN}$ \\
\hline T60\% Recovery & 269 & 290 & 290 & 278 & 277 & 282 & 290 & 282,286 & 8,149 & 298,583 & 265,988 & 2,887 & $\mathrm{IN}$ \\
\hline T70\% Recovery & 304 & 310 & 308 & 300 & 305 & 305 & 310 & 306,000 & 3,445 & 312,890 & 299,110 & 1,126 & $\mathrm{IN}$ \\
\hline T80\% Recovery & 334 & 328 & 326 & 327 & 326 & 330 & 329 & 328,571 & 3,082 & 334,736 & 322,407 & 0,938 & IN \\
\hline T90\% Recovery & 368 & 360 & 358 & 364 & 364 & 364 & 365 & 363,286 & 3,521 & 370,328 & 356,243 & 0,969 & IN \\
\hline \multicolumn{14}{|l|}{ T95\% Recovery } \\
\hline FBP & 371 & 371 & 371 & 371 & 371 & 371 & 371 & 371,000 & 0,000 & 371,000 & 371,000 & 0 & \\
\hline
\end{tabular}
oleh Araujo et. al., 2021, dimana pada penelitian tersebut dilakukan uji distilasi pada Biosolar jenis B5, B10, B15, B20, B30, dan B50.

Tabel 1 Uji Keseragaman Hasil Distilasi Solar Kilang 
Tabel 2 Uji Keseragaman Hasil Distilasi Biosolar B30

\begin{tabular}{|c|c|c|c|c|c|c|c|c|c|c|c|c|c|}
\hline BIOSOLAR B30 & 1 & 2 & 3 & 4 & 5 & 6 & 7 & $M E A N$ & SD & UCL & LCL & RSD & KET \\
\hline IBP & 168 & 169 & 160 & 169 & 168 & 169 & 168 & 167,286 & 3,545 & 174,376 & 160,196 & 2,119 & IN \\
\hline T10\% Recovery & 216 & 217,5 & 208 & 209 & 211 & 211 & 210 & 211,786 & 3,826 & 219,439 & 204,133 & 1,807 & IN \\
\hline T20\% Recovery & 241,5 & 246,5 & 235 & 241 & 245 & 245 & 243 & 242,429 & 4,191 & 250,811 & 234,046 & 1,729 & IN \\
\hline T30\% Recovery & 265 & 268 & 260 & 266 & 268 & 269 & 268 & 266,214 & 3,293 & 272,800 & 259,629 & 1,237 & IN \\
\hline T40\% Recovery & 285 & 284,5 & 279 & 285 & 281 & 285,5 & 283 & 283,286 & 2,677 & 288,640 & 277,932 & 0,945 & IN \\
\hline T50\% Recovery & 299,5 & 301 & 291 & 299 & 302 & 301,5 & 298 & 298,857 & 4,087 & 307,030 & 290,684 & 1,367 & IN \\
\hline T60\% Recovery & 311,5 & 312 & 307 & 311 & 311 & 312 & 311 & 310,786 & 1,891 & 314,567 & 307,004 & 0,608 & IN \\
\hline T70\% Recovery & 321 & 321 & 319 & 321 & 322 & 322 & 320 & 320,857 & 1,095 & 323,048 & 318,666 & 0,341 & IN \\
\hline T80\% Recovery & 329 & 329,5 & 327 & 329 & 330 & 329,5 & 328 & 328,857 & 1,049 & 330,955 & 326,760 & 0,319 & IN \\
\hline T90\% Recovery & 339,5 & 339,5 & 339 & 340 & 341 & 340 & 340 & 339,714 & 0,516 & 340,747 & 338,681 & 0,152 & IN \\
\hline T95\% Recovery & 351,2 & 353 & 348 & 353 & 355 & 353 & 354 & 352,386 & 2,383 & 357,152 & 347,619 & 0,676 & IN \\
\hline FBP & 355 & 360 & 350 & 355 & 358 & 364 & 359 & 357,286 & 4,817 & 366,919 & 347,652 & 1,348 & IN \\
\hline
\end{tabular}

Sedangkan hipotesis yang menyatakan bahwa rerata (mean) dari Solar kilang dan solar B-30 adalah sama diambil secara acak dari populasi yang sama $\left(\mu_{1}=\mu_{2}\right)$ dengan menggunakan metode statististika uji t. Uji $\mathrm{t}$ dilakukan guna menentukan ada tidaknya perbedaan rerata (mean) yang siknifikan antara suhu distilasi Solar kilang dengan solar B-30. Dari hasil uji t ini dinyatakan tidak terdapat perbedaan signifikan antara hasil uji distilasi pada solar B-30 dan Solar kilang pada confidence level 0,05. Sehingga metode uji distilasi dengan menggunakan metode standar ASTM D86-17 bisa digunakan untuk uji Solar B-30.

Dari tabel diperoleh bahwa nilai |t-hitung| $>$ t-tabel sehingga hipotesis H0, yang menyatakan bahwa rerata (mean) kedua sampel berasal dari populasi yang tidak sama dan terdapat perbedaan yang signifikan pada

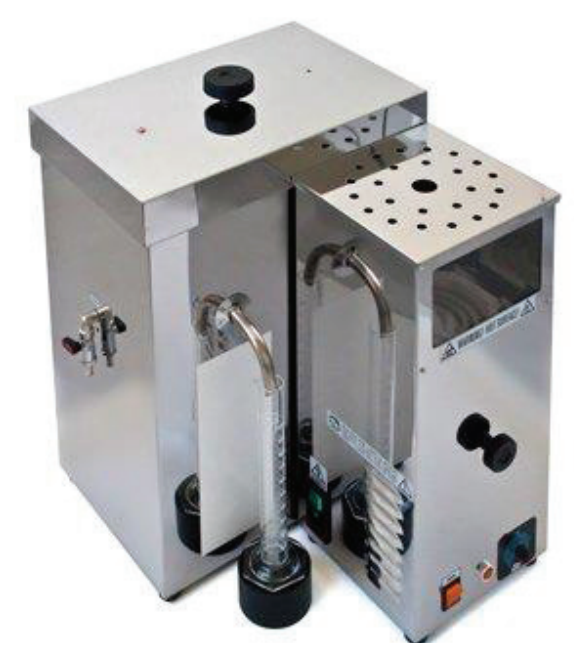

Gambar 1. Alat Uji Distilasi ASTM D-86

confidence level 0,05. Selain hal tersebut, dilihat dari nilai $p_{\_}$value nya yang kurang dari 0,05 ( $p \_$value $<0,05$ ). Maka $\mathrm{H} 0$ ditolak, sehingga kedua sampel tidak berasal dari 
populasi yang sama (berasal dari populasi yang berbeda). Hal tersebut dapat dilihat dari kurva hasil distilasi antara Solar kilang dengan Biosolar B-30, dimana kedua sampel tidak saling berhimpit akan tetapi terjadi perbedaan atau simpangan yang cukup besar.

\begin{tabular}{|c|c|c|c|}
\hline & $1 \mathrm{ab}$ & Iasil & \\
\hline \multirow{2}{*}{$\mathrm{T} \% \operatorname{Rec}$} & \multicolumn{2}{|c|}{ Hasil Uji F } & \multirow{2}{*}{ Keterangan } \\
\hline & F Hitung & F Tabel & \\
\hline IBP & 1,383 & 2,447 & F-stat $<$ F-tab \\
\hline 10 & 1,712 & 2,447 & F-stat $<$ F-tab \\
\hline 50 & 2,205 & 2,447 & F-stat $<$ F-tab \\
\hline 90 & 2,4 & 2,447 & F-stat $<$ F-tab \\
\hline FBP & 0 & 2,447 & F-stat $<$ F-tab \\
\hline
\end{tabular}

\begin{tabular}{cccc}
\multicolumn{4}{c}{ Tabel 4. Hasil Uji t } \\
\hline \multirow{2}{*}{ T \%Rec } & \multicolumn{2}{c}{ Hasil Uji t } & Keterangan \\
\cline { 2 - 4 } & t Hitung & t Tabel & \\
\hline IBP & $-2,033$ & 2,179 & {$[$ t-stat $]<$ t-tab } \\
10 & $-6,277$ & 2,179 & {$[$ t-stat $]<$-tab } \\
50 & $-14,133$ & 2,179 & {$[$ t-stat $]<$ t-tab } \\
90 & 73,515 & 2,179 & {$[$ t-stat $]>$ t-tab } \\
FBP & 8,133 & 2,179 & {$[$ t-stat $]>$ t-tab } \\
\hline
\end{tabular}

Perbedaan tersebut disebabkan karena Biosolar B-30 memiliki kandungan FAME yang lebih tinggi yang memungkinkan sifat volatilitas Biosolar B-30 cenderung menurun akibat jenis/sumber minyak nabati yang terkandung didalamnya. Sehingga suhu recovery distilasinya meningkat atau lebih tinggi dari pada Solar kilang.

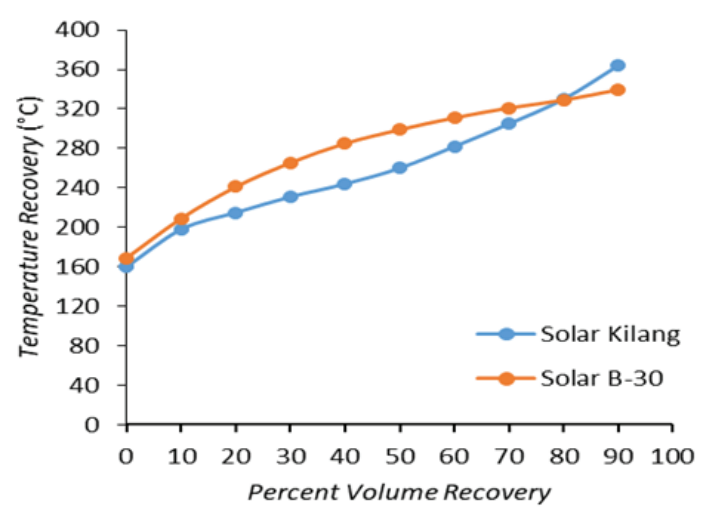

Gambar 2. Profil distilasi ASTM D86 Solar Kilang dan Solar B-30
Berdasarkan grafik perbandingan hasil distilasi di atas menunjukkan trend grafik yang berbeda antara Biosolar B-30 dengan Solar kilang. Dimana pada Biosolar B-30 memperlihatkan bentuk kurva hasil distilasi yang lebih melengkung ke atas dibandingkan dengan kurva hasil distilasi pada Solar kilang. Menurut Araujo (2021), hasil distilasi Biosolar dengan ASTM D86-17 menunjukkan semakin tinggi kandungan FAME pada Biosolar kurva distilasi yang diperoleh semakin melengkung ke atas.

\section{KESIMPULAN}

Berdasarkan uji $\mathrm{F}$ yang telah dilakukan metode ASTM D86-17 dapat digunakan sebagai metode uji distilasi pada Biosolar B30. Hasil distilasi antara Solar kilang dan Biosolar B30 menunjukkan bahwa rerata (mean) kedua data relatif sama dan tidak terdapat perbedaan yang signifikan.

\section{DAFTAR PUSTAKA}

Araujo, A. S., Fernandes, V. J., Silva J. B., Almeida, J. S., Barbosa, R. V., Fernandes, G. J. T., and Coriolano, A. C. F., 2021, Thermal oxidative stability of biodiesel/ petrodiesel blends by pressurized differential scanning calorimetry and its calculated cetane index, Processes, 9, 174184.

ASTM Standar D86-17, 2017, "Standar Test Method for Distillation of Petroleum Products and Liquid Fuel at Atmospheric Pressure1," ASTM International, USA, 2017

Lin, C. Y., and Ma, L., 2020, Influences of water content in feedstock oil on burning characteristic of fatty acid methyl esters, Process, 8, 1130-1144. 